our negotiators have given that profit away to our non-dispensing colleagues who have as their own "perks" bigger lists, factory and hotel retainers, boarding schools, and extra insurance examinations, and have their practices within short distances of their surgeries with considerably less travelling. I am amazed to find that our organisation has only found after 36 years that dispensing profits and losses are tied to the general general practitioner remuneration. I thought the "pool" was scrapped in the 1960s. I feel that I have been "sold out" by the establishment men, first to the retail chemists and now to the Department of Health and Social Security.

Edington,

W P HAYNE

Bridgwater

SIR,-Our negotiators are pleading for a fee for carrying out cervical cytology testing on the grounds that general practitioners should not do work without payment. Yet it seems perfectly all right to accept payment for doing no extra work. I refer to the nondispensing general practitioners taking around $£ 1000$ per annum of my earned income as a dispensing general practitioner.

I run a business which takes extra time, effort, staff, and capital. I see no good reason why those who do not have this responsibility or work should share in the profits. This is yet another example of the incompetence of our negotiators. First we had the iniquitous Clothier settlement which swayed the balance in favour of the chemists. As a member of the local dispensing subcommittee I understand the imbalance which was imposed on us there. Now we have an attack from the British Pharmaceutical Society on our total incomes from dispensing on one side and an attack from our envious general practitioner colleagues on the other. Small wonder that dispensing doctors feel persecuted. We have no separate representation and therefore no voice in these matters. If my dispensing colleagues would care to contact me perhaps we can remedy this.

Husbands Bosworth,

F D ROBERTS

Lutterworth,

${ }^{*} *$ The secretary writes: "Payment for dispensing has two elements: there is the direct reimbursement of the cost of the medicine and container, and payment of a dispensing fee and an on cost allowance to cover professional work and responsibility, capital investment, and those expenses not directly reimbursed. The direct reimbursement of any expense, whether the cost of drugs, staff salaries, rent or rates, etc, at a rate greater than the expense actually incurred does not cost the Department of Health and Social Security additional money but results in there being less available for the payment of expenses indirectly through fees and allowances. A discount scale is being introduced from 1 July 1984 to correct this maldistribution of practice expenses. The element to cover work done, indirect expenses, capital investment, etc, is determined by the review body. That element has been increased in line with remuneration generally - that is, from $15 p$ per. prescription in 1967 to around $88 p$ per prescription in 1983. This compares with an increase in intended net remuneration from $£ 3700$ in 1967 to $£ 20670$ in 1984." -

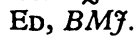

\section{Breaking bad news}

SIR,-We congratulate Dr Robert Buckman on his article (26 May, p 1597). For the past few years we have attempted to give clinical medical students a seminar on communicating sensitive and threatening information to their patients. This usually takes the form of simulated consultations and discussion. The group is limited to 12 students at any one time. Several points of interest have emerged.

Students find it difficult to admit clinical ignorance, and knowing all the answers is seen as the best defence against difficult questioning. No student has ever acquiesced in the shielding of "patients" from unpalatable information although he may have seen this practised in other parts of his clinical course. Some students tend to err on the side of brutal frankness. Most, however, are clearly at pains to respond sympathetically to the "patient's" questions. A few students feel that such a seminar is not part of their "serious" curriculum, but most welcome the chance to discuss communication problems and a few have mentioned that they found the session useful when they subsequently qualified.

Role play with clinical students taking the parts of doctor, patient, and relative has been more successful than we expected at the outset two and a half years ago. It can be both entertaining and occasionally moving. We feel it is important to "de-role" during the subsequent discussion. Other departments of the hospital have independently felt the need for a teaching and discussion session on communication skills, including the departments of general practice, psychiatry, and the school of nursing. They too use role play. We believe that students must not be excluded from real conversations when bad news is discussed. Such consultations, however, must not be distorted by the presence of an "audience." For this reason no more than two students at a time accompany us on a ward round or in the clinic. We agree with Dr Buckman that the ability to communicate with patients is an acquired skill and needs to be taught, but we also believe that most medical students are intrinsically spontaneous communicators, and that we should prevent this ability being overlaid by a veneer of clinical acumen.

A $M$ Hoy

BARBARA M SAUNDERS MiCHAEL KEARNEY

St Thomas's Hospital,

London SE1 7EH

SIR,-I find the title of Dr Robert Buckman's article (26 May, p 1597) incorrect. In a relationship with a patient two factors are required: compassion and time. Compassion you either have or you don't, time you can make. So called bad news implies telling patients with cancer that they have it. If cancer were put into the same category as other chronic diseases such as cardiovascular disease, neurological disorders, and diabetes ${ }^{\circ}$ it would imply that having cancer is not necessarily a death sentence.

The doctor's own fears about a particular disease may be transferred to the patient's comprehension of his or her condition. Recently a 22 year old girl with metastatic renal cancer came for a second opinion. She had not been told that she had cancer, and her parents' wish was that she be told although they were anxious about her reaction. The surgeon had told her that a "cyst" had been removed. When told the truth she was relieved to have an explanation for her symptoms and expressed anger at not having been told straight away. You can cope with being told you have cancer providing compassion and time are both plentiful. The doctor should be able to outline the proposed treatment at the time the patient is first told.

Recent films and the constant outpourings of television are well able to inform potential patients. Discussions with patients have nothing to do with traffic wardens, badges of authority, making patients cry, blaming anyone, or saying sorry. Doris Day's song "Que Sera Sera" says most of it. Being kind and decent, sitting down with the patient, preferably holding his or her hand, and being available again and again does the rest.

JOHN P GLEES

Royal Marsden Hospital,

Sutton,

Surrey'SM2 5PT

\section{Unfairness in oral exams}

SIR,-Dr B W Perriss is correct (5 May, p 1383); the primary FFA is not an easy exam. In fact it is so difficult that when a few years ago the examiners were invited to sit the multiple choice paper most of them failed. Dr Perriss is incorrect: candidates who do not pass the multiple choice paper are not invited to the oral, but receive a partial refund of fee. Candidates must satisfy the examiners in every section. The oral exam is an inexact method of testing scientific subjects, as shown by $\mathrm{Dr}$ Perriss's examples of passing or failing examinees. This is the main reason why most colleges have abandoned it.

Dr Perriss's observations that "many nonwhites (particularly those from the Indian subcontinent) do not have a grasp of basic physiology, pharmacology, and physics" are at variance with the fact that the largest number of non-Europid consultant anaesthetists are from the Indian subcontinent. Why are there no non-Europid examiners ?

Since my letter (14 April, p 1158) I have had many responses and only two, including Dr Perriss's, have disagreed with me. It is probable that most examinees feel that the oral exam of the primary FFA is unfair and should be abandoned. From 1985 the FFA will be in three parts (with orals in each part of course), and not two as at present. Thus, in contrast to all other postgraduate examining bodies, the Faculty of Anaesthetists will increase its income from exams by about a third at a stroke. It is probable that we will learn more and more about less and less, but it is unlikely that an additional exam will improve the anaesthetic management of patients.

HAYDN DIDIER

St Peter's General Hospital, Chertsey,

\section{ABC of Asthma}

SIR,-Dr John Rees states: "Exercise itself is unlikely to have any major beneficial effect on the asthma. ... Asthma is quite compatible with a successful sporting career, as a number of athletes have testified in manufacturers' advertisements" (19 May, p 1512). As the medical adviser to the company that worked 
with the sportsmen to prove the latter statement I was struck by the inverse relation between the severity of their asthma and their state of physical fitness. If they stopped or reduced their training their symptoms became more noticeable and treatment had to be increased.

This was the main reason for encouraging the formation of activity groups for asthmatic children to increase confidence and fitness. It is difficult to prove that physical training reduces the severity of asthma and this was the main controversy at a symposium held in 1982..$^{1}$ Asthma remains an important cause of morbidity and hospital admissions among children and it would seem useful to establish whether active participation in training programmes is an important part of management.

Alan M Edwards

Pickwell

Melton Mowbray LE14 2QT

${ }^{1}$ Oseid S, Edwards AM, eds. The asthmatic child in play and sport. London: Pitman Medical 1983.

SIR,-Dr John Rees states that: "Children with asthma usually show normal growth unless they have received long term treatmen with systemic corticosteroids, though puberty may be delayed when asthma is severe" (12 May, p 1441). We appreciate that his article must be succinct but feel that this statement is inaccurate and may deter readers from the essential monitoring of growth in affected children.

The effects of systemic corticosteroids on growth are well recognised but several workers have described a tendency to short stature and retarded bone age in asthmatic children who have never received, or have had only short courses of, systemic corticosteroids. ${ }^{1-5}$ The degree of growth delay correlates with the clinical severity of the disease and is manifested at adolescence as delayed puberty with attendant short stature. ${ }^{6}$ Adult height is nearly always within the genetic expectations, although it is achieved at a later age. Growth delay, however, may manifest itself at a much earlier age. If asthmatic children are compared with the general population or with normal and atopic but non-asthmatic controls they show a decreased mean height and retarded mean bone age. ${ }^{78}$ This would not support the statement that growth is usually normal.

In children the severity of the asthma may not be apparent from the clinical history, examination, or occasional simple lung function measurements; but inspection of the growth pattern may provide useful information on the adequacy of long term treatment. Furthermore, an increase in growth velocity may be observed in asthmatic children whose treatment is adjusted to improve control, even when this involves the use of inhaled corticosteroids. ${ }^{8}$ We consider that accurate monitoring of growth is essential in asthma and indeed all chronic diseases of childhood.

C M LAW

Department of Growth and
Development,

Institute of Child Health,

London WCIN $1 \mathrm{EH}$

J O WARNER

Brompton Hospital,

Fulham Road,
' Preece MA. The effect of administered corticosteroids on the $625-30$.

'Hauspie R, Susanne C, Alexander F. Maturational delay and temporal growth retardation in asthmatic boys. F Allergy Clin Immunol 1977;59:200-6. unyder RJ, Collip PJ, Greene JS. Growth and 1967;6:389-92.

- Murray AB, Fraser B, Hardwick DF, Pine G. Chronic asthma and growth failure in children. Lancet 1976;ii:197.

'Dawson B, Horobin G, Illsley R, Mitchell RE. A survey of childhood asthma in Aberdeen. Lance 1969 ;i :827-30.

- McNicol KM, Williams HB. Spectrum of asthma in children. I Clinical and physiological components.
$B r$ Med $\mathcal{F} 1973$;iv $: 7-11$. Hauspie R, Susanne

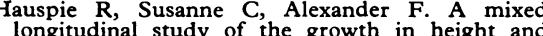
weight in asthmatic children. Hum Biol $1976 ; 48$. weight

8 Taylor B, Norman AP. Betamethasone 17-valerate in
childhood asthma. Acta Paediatr Scand $1975 ; 64$. 234-40.

${ }^{*}{ }^{*}$ Dr Rees replies below.-ED, $B M F$.

SIR,-Dr Law and Dr Warner make an important point, particularly as childhood asthmatics are sometimes treated in adult clinics, where growth assessments are not routinely made. I agree that growth should be carefully monitored, since delay is a significant finding indicating the need to change treatment to improve disease control. Growth delay caused by asthma is associated with severe airflow obstruction and persistent hypoxia which are found in only a small minority of childhood asthmatics when suitably managed. ${ }^{2}$ Adequacy of control is best assessed by activity and peak flow recordings, which can be performed from around the age of 4 years. Progress of weight and height may give additional valuable information on long term control and should certainly be monitored in children.

Guy's Hospital,

JOHN REES

London

' McNicol KM, Williams HB. Spectrum of asthma in children. I. Clinical and physiological components. children. I. Clinical and

${ }^{2}$ Murray AB, Fraser B, Hardwick DF, Pirie G. Chronic asthma and

\section{Postmarketing surveillance of adverse} drug reactions

SIR,-Dr W M Castle and Dr J A Lewis accuse me of providing misleading statistics and of selecting the numbers of patients who might be recruited for formal postmarketing surveillance studies on an arbitrary basis (12 May, p 1458).

At the time that a new drug is marketed only about 1000 patients may have been treated with it. This is usually sufficient to establish efficacy and short term safety for more frequent adverse reactions, but it is inadequate for the evaluation of longer term safety or to assess the drug's propensity for producing less frequent (albeit serious) adverse effects. The techniques of postmarketing surveillance, such as those cited in my leading article (24 March, p 879), are designed to extend knowledge about the safety of a new drug. As I stated quite clearly (using italics and quotations marks), such studies detect adverse "events." Interpreting the toxicological importance of these events requires examination of the data as well as a control population. Whether or not a difference in the frequency of a particular "event" between the drug treated and control groups reaches conventional (arbitrary) levels of statistical significance depends on several factors, including the size of the difference and the background incidence of the event under question. Obviously, where the "event" is a very rare adverse reaction, or where there is a high background incidence, postmarketing surveillance may be inadequate. The suggestion that postmarketing surveillance studies should be dismissed, as Dr Castle and Dr Lewis suggest, because they cannot detect an increase in the incidence of diabetes from $1 \%$ to $1.3 \%$, or of impotence from $10 \%$ to $10.03 \%$, is quite literally reductio ad absurdum.

Like all other decisions based on statistical probabilities, my estimates of the numbers of patients required for postmarketing surveillance studies are entirely arbitrary. If such studies are to make a serious attempt to extend knowledge about the human toxicology of a new product, then the number of patients included should be an order of magnitude greater than those in the premarketing investigation and anything much less is probably not worth the trouble or expense. Since at least 1000 patients are usually studied in premarketing investigation it follows that at least 10000 patients are needed for postmarketing ones.

Postmarketing surveillance techniques do not solve all the problems of adverse reaction monitoring. They complement, rather than substitute for, other methods. They do, however, provide one useful and important way to identify less common adverse drug reactions, and estimate their incidence. Without this information it is impossible to evaluate the long term risks or benefits.

M D RAWLINS

Wolfson Unit for Clinical

Pharmacology,

University of
upon Tyne,

Newcastle upon Tyne NE1 7RU

\section{Association of hyperglycaemia with hyponatraemia}

SIR,-Dr E Walters and Dr Lavinia Hallam (14 April, p 1146), showed that hyperglycaemia is found in $18 \%$ of patients with hyponatraemia. We have also carried out a retrospective analysis of results on six randomly selected days (2480 samples)

A total of 87 patients $(3.5 \%)$ had hyponatraemia (plasma sodium concentration $<130 \mathrm{mmol}(\mathrm{mEq}) / \mathrm{l})$ and a blood glucose concentration was available in $52(60 \%)$ of these. It was above $11 \mathrm{mmol} / 1(198 \mathrm{mg} / 100 \mathrm{ml})$ in eight patients $(15 \%)$. In a control group (plasma sodium concentration 130-144 $\mathrm{mmol}(\mathrm{mEq}) / \mathrm{l})$, four out of $95(4 \%)$ had a blood glucose concentration $>11 \mathrm{mmol} / \mathrm{l}$.

Dr Walters and Dr Hallam included nine patients on intravenous fluids. Hyperglycaemia could not be confirmed in a subsequent sample in one of these patients and the blood sample was obtained from the drip arm in another. Two samples were obtained from patients after surgery who were receiving 5\% dextrose. Water overload, stress induced hyperglycaemia, and postoperative antidiuretic hormone release could all contribute to the abnormalities seen. Among the 10 patients not on intravenous fluids four patients were taking diuretics and in one hyperglycaemia could not be confirmed. Of our eight patients with hyperglycaemia and hyponatraemia six had either liver or renal disease. Both of these conditions can cause glucose intolerance and 